\title{
Influence of Coating Method on the Performance of Roll- to-Roll Coated PEM Fuel Cell Catalyst Layers
}

Scott Mauger

$20^{\text {th }}$ ISCST Symposium

September 21, 2020 


\section{Proton Exchange Membrane Fuel Cells}

- Light duty vehicles (LDV), heavy duty trucking, trains, marine transportation, stationary power

- High efficiency (>2x internal combustion)

- Zero GHG emissions

- Long-range EV (LDV - 300+ miles/tank)

- Short refueling time (LDV - $5 \mathrm{~min}$ )

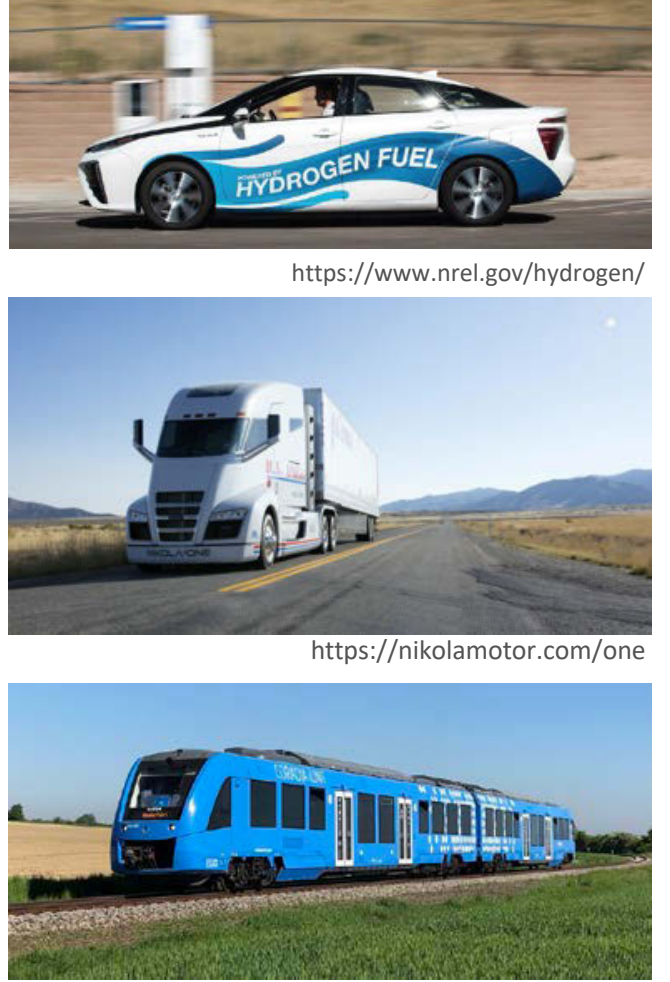




\section{Fuel Cell Structure}

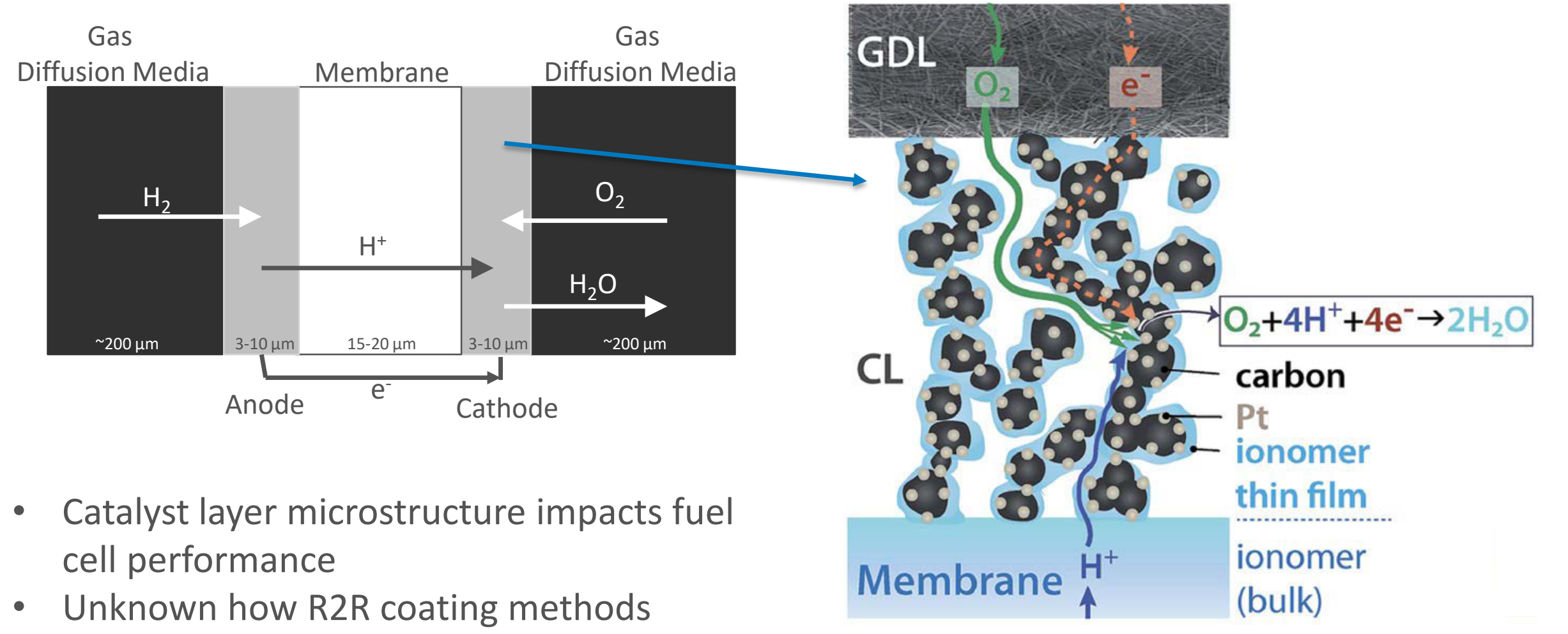

impact catalyst layer structure 


\section{Experimental}

\section{$\underline{\text { Slot Die Coating }}$}

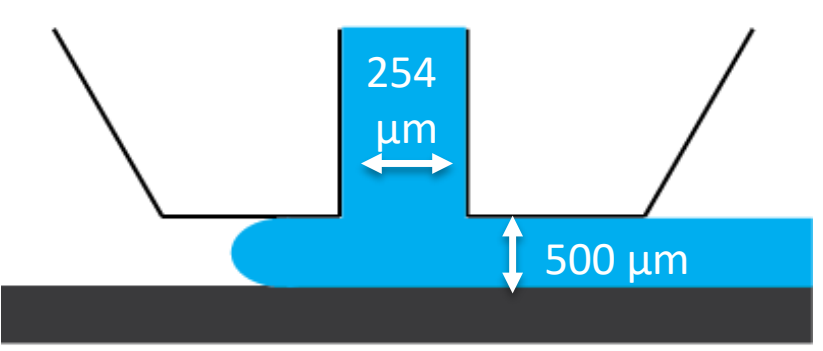

Web Direction

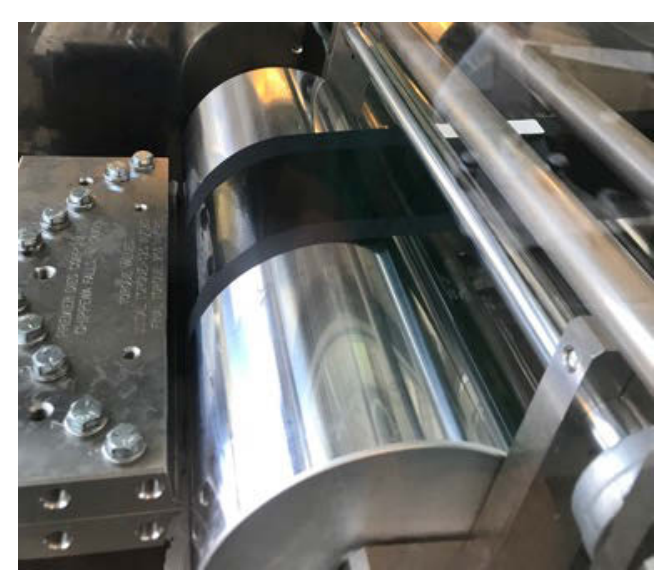

25 lines/inch $170 \mathrm{~cm}^{3} / \mathrm{m}^{2}$ b)

Gravure Coating
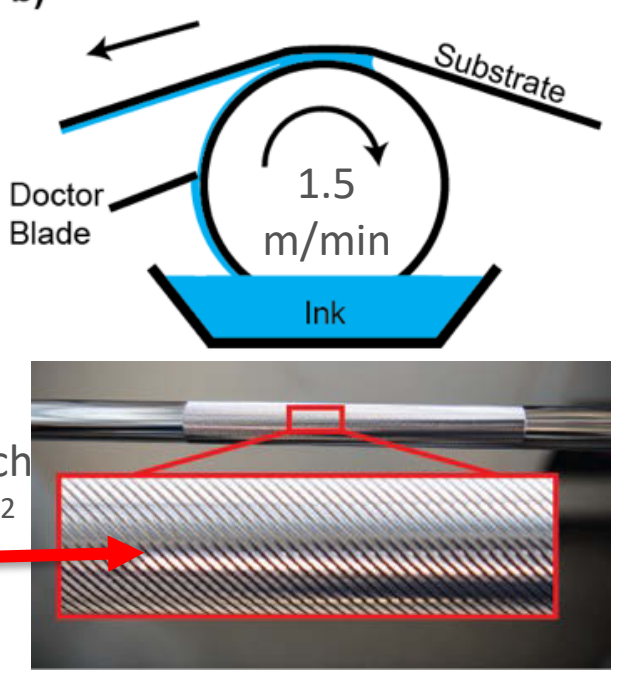

Mauger, S. A.; et al.; J Electrochem Soc 2018, 165 (11), F1012-F1018. https://doi.org/10.1149/2.0091813jes.

Web Speed: $1 \mathrm{~m} / \mathrm{min}$ Oven Temp: $80^{\circ} \mathrm{C}$ Substrate: diffusion media
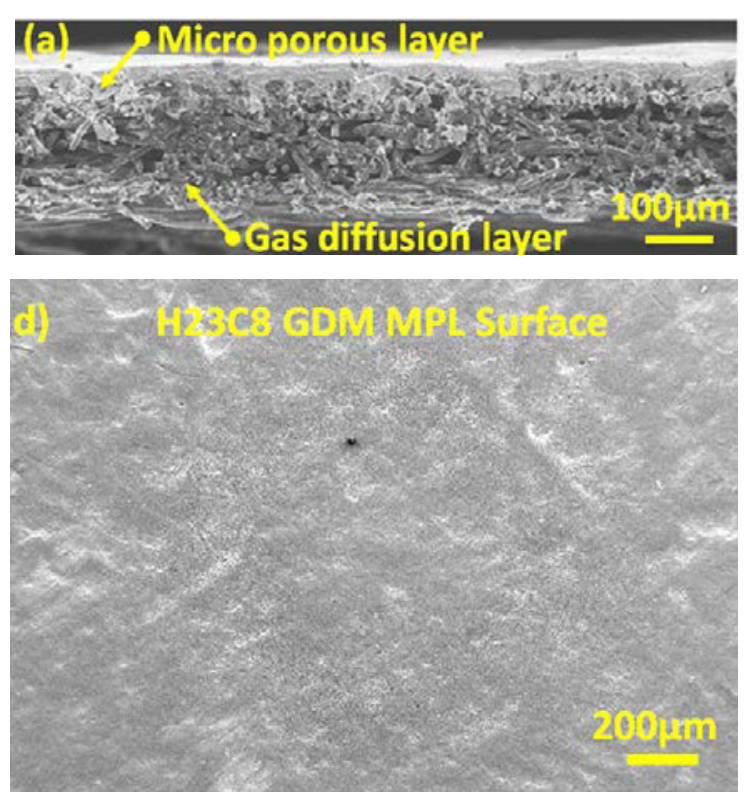

Wang, M.;. ACS Appl. Energy Mater. 2019, 2 (11), 7757-7761. 


\section{Fuel Cell Performance}

$0.12 \mathrm{mg}_{p_{\mathrm{pt}}} / \mathrm{cm}^{2}$
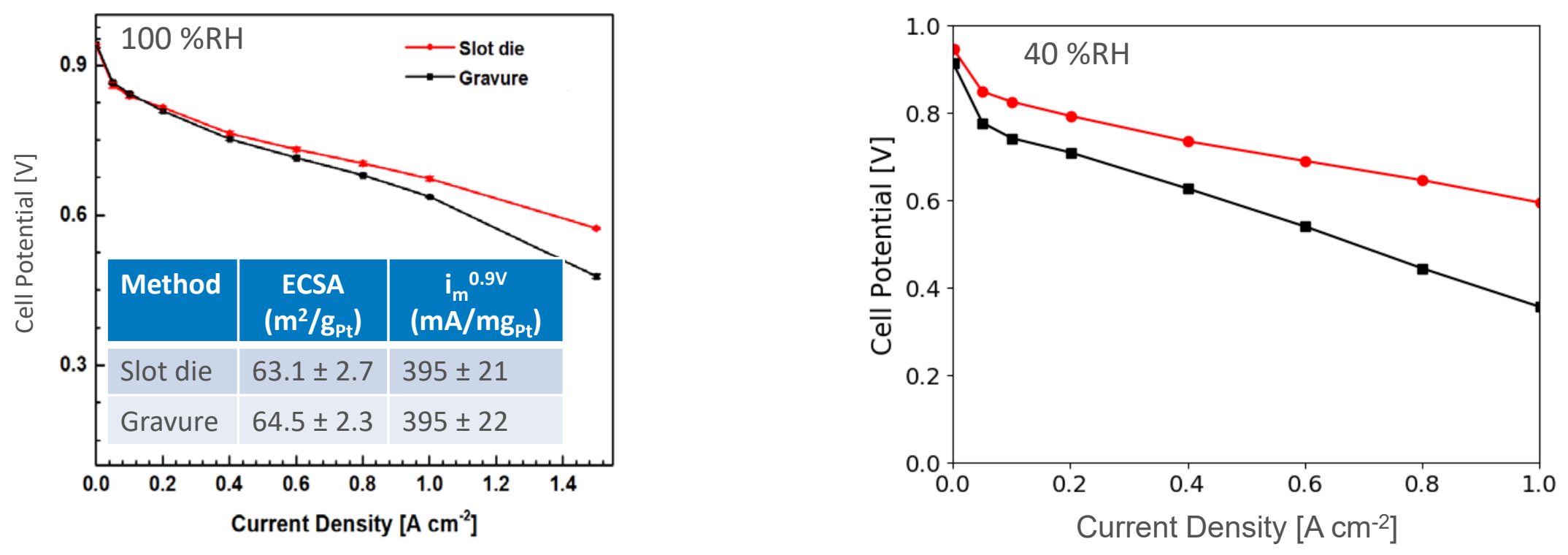

At $100 \% \mathrm{RH}$

- No differences in kinetics

- Slot die better at high current densities

At $40 \% \mathrm{RH}$

- Large difference in kinetics

- Slot die better at all current densities 


\section{Electrochemical Surface Area}

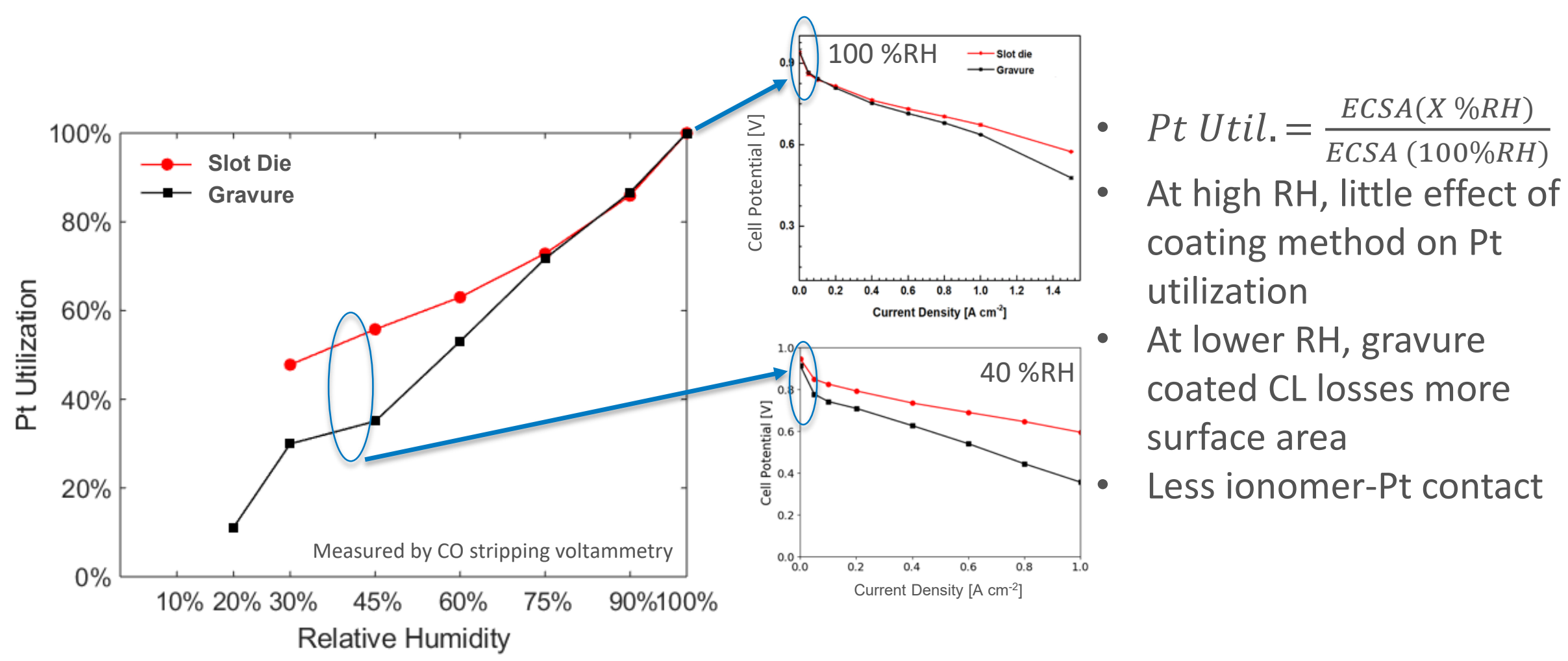




\section{$\mathrm{H}_{2} / \mathrm{N}_{2}$ Electrochemical Impedance Spectroscopy}

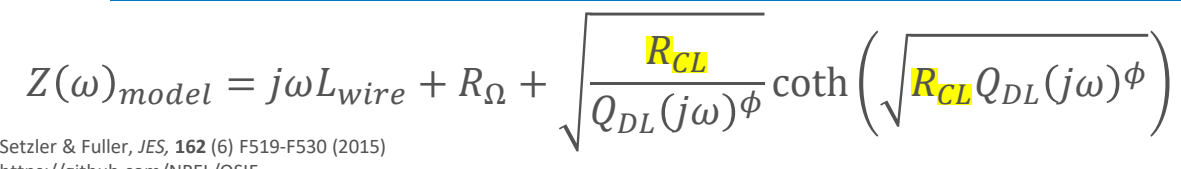
Setzler \& Fuller, JES, 162 (6) F519-F530 (2015)
https://github.com/NREL/OSIF
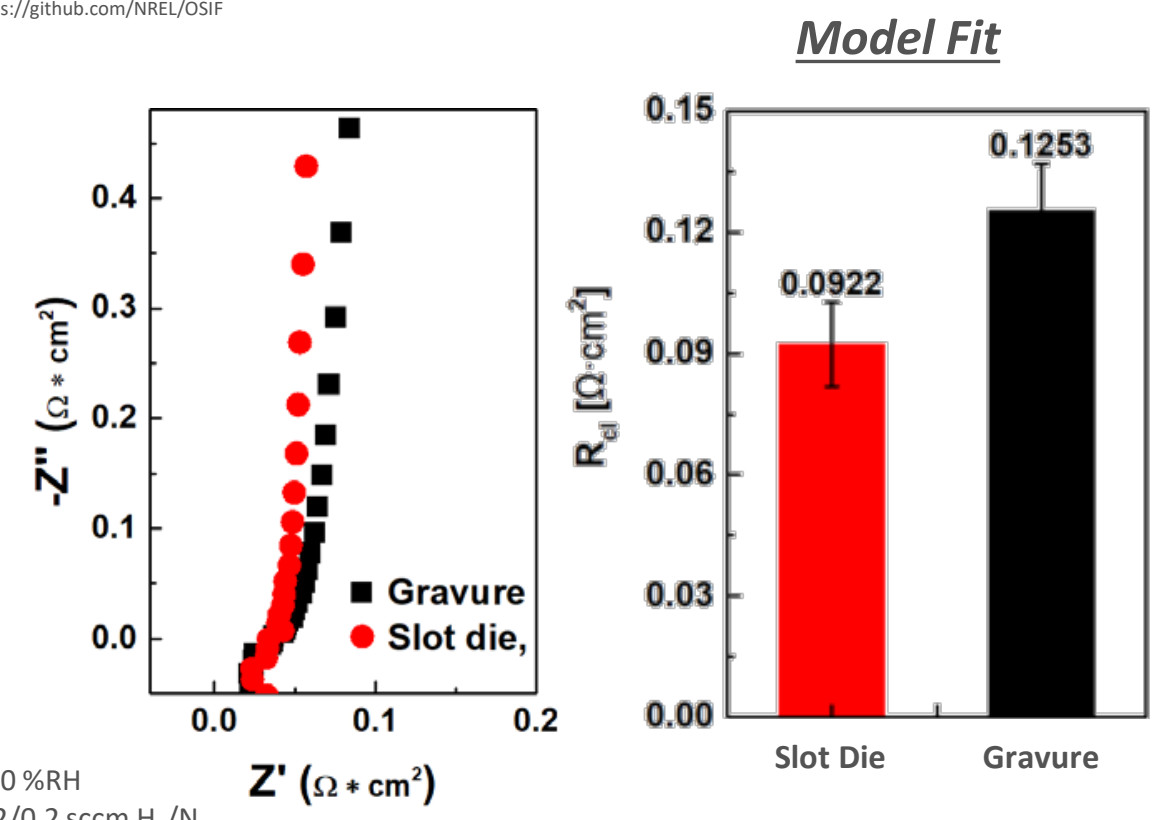

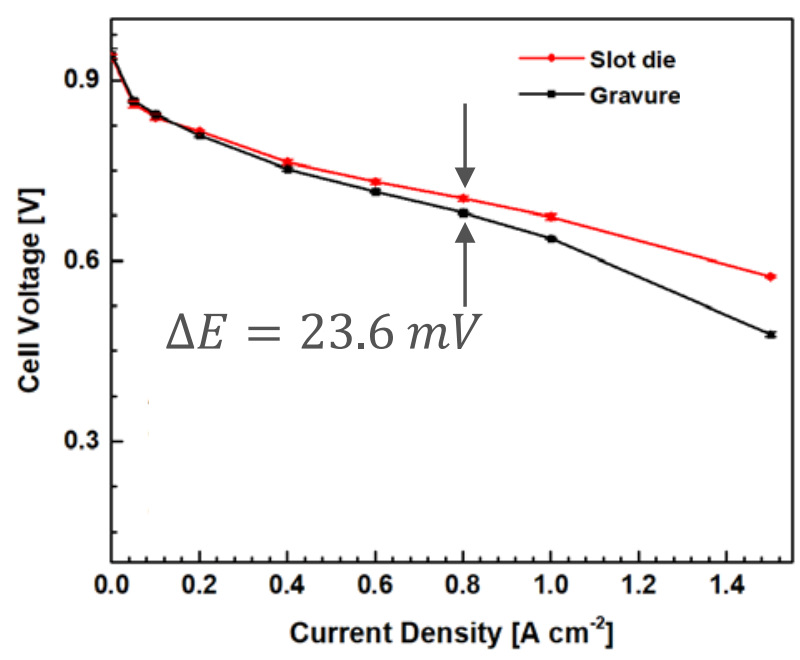

$\Delta R_{C L}=33.1 \mathrm{~m} \Omega \cdot \mathrm{cm}^{2}$

$\Delta E=i \Delta R_{C L}$

$\Delta E\left(0.8 \frac{A}{c^{2}}\right)=26.5 \mathrm{mV}$

Why does Gravure have higher resistance

- Higher tortuosity/fewer conduction pathways

- Lower surface ionomer content 


\section{Catalyst Layer Microscopy}

Scanning Transmission Electron Microscopy

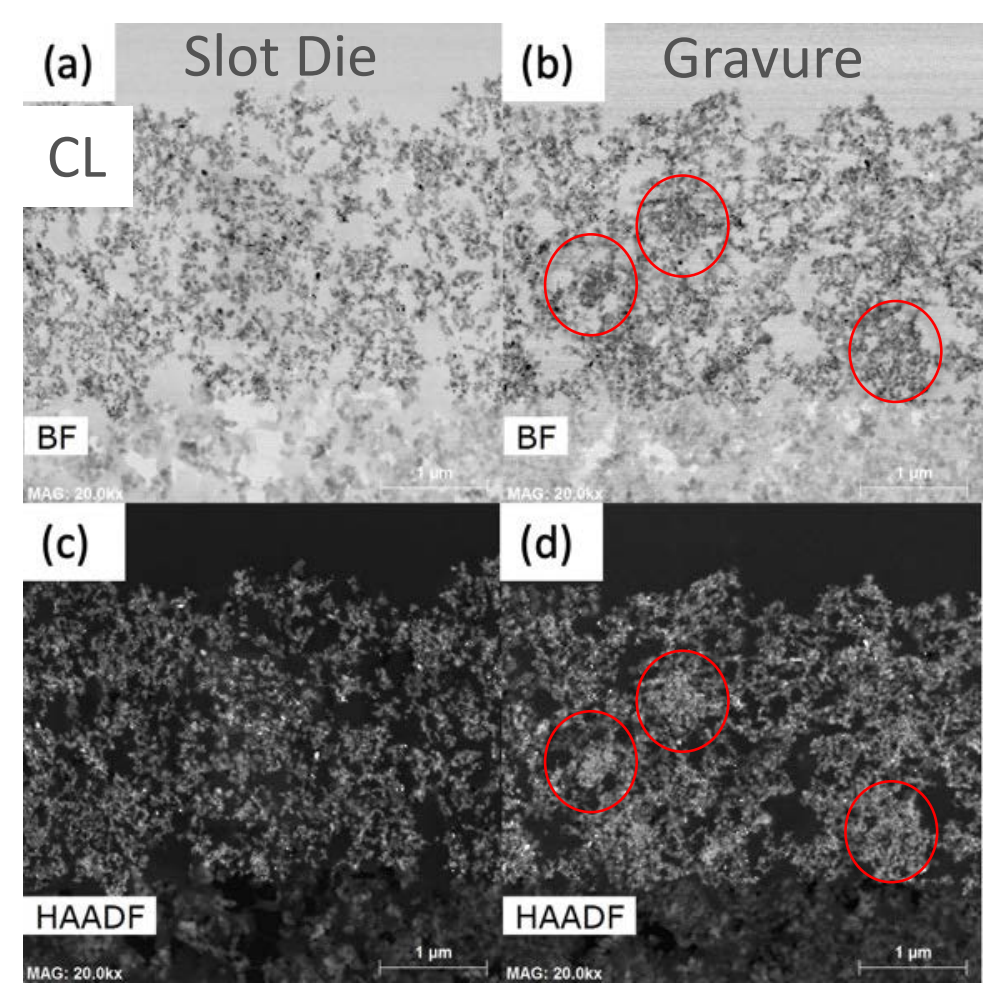

- Gravure results in more clustered, denser catalyst layer

- Dense clusters lead to lower ionomer accessibility to catalyst lower ECSA at low RH

- If ionomer is less dispersed it could lead to fewer proton conduction pathways 


\section{Catalyst Ink Rheology}

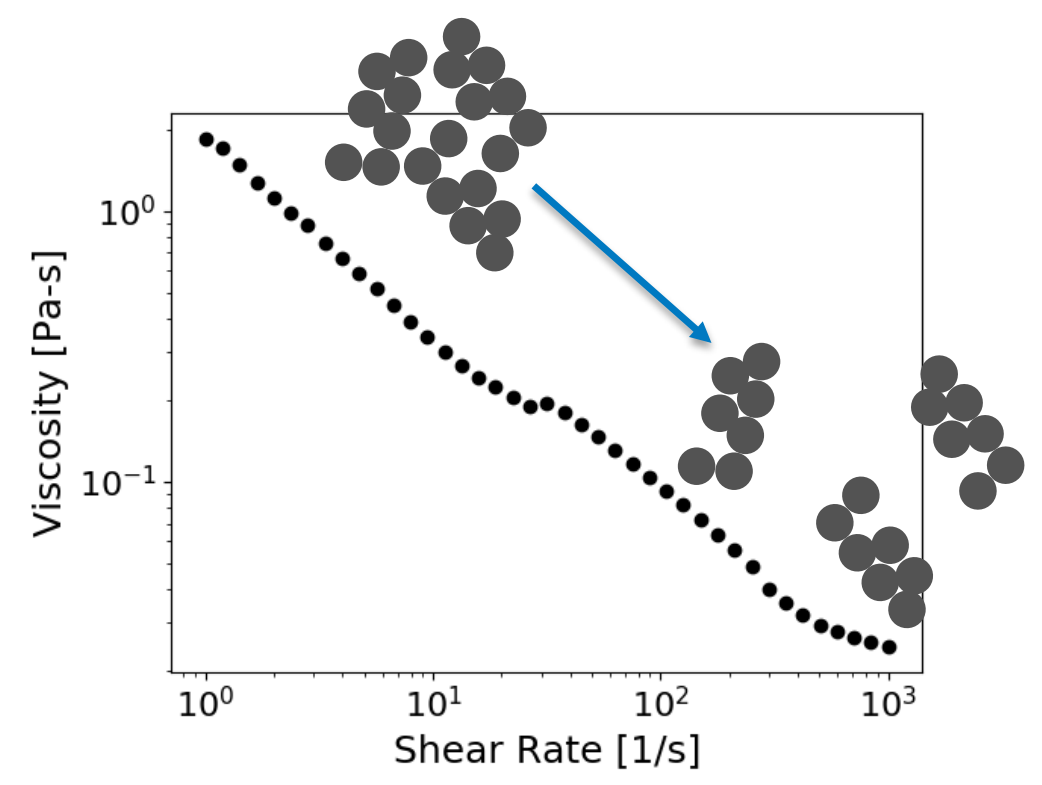

- Catalyst inks are weakly agglomerated

- Shear thinning due to agglomerate break up

- Could the different shear rates of coating processes impact catalyst layer microstructure 


\section{How does coating method effect}

\section{microstructure}

\section{Slot Die}

- In Die Body - Plane Poiseuille

- $\dot{\gamma}=\frac{6 Q}{W^{2}}\left(1-\frac{y}{W}\right)$

- $\operatorname{Avg} \dot{\gamma} \approx 4 s^{-1}$

- In coating gap - Poiseuille/Couette

- $\dot{\gamma}=\frac{6 Q}{L H^{2}}\left(1-\frac{2 y}{H}\right)+\frac{V}{H}\left(\frac{6 y}{H}-4\right)$

- Avg $\dot{\gamma} \approx 50 s^{-1}$

- In tubing to die - Pipe Poiseuille

- $\dot{\gamma}=\frac{-4 Q r}{\pi R^{4}}$

- Avg $\dot{\gamma} \approx 110 s^{-1}$

- Avg residence time in tube $\approx 12 \mathrm{~s}$
Gravure

- Shear profile not analytically solvable

- Low shear in gravure cell

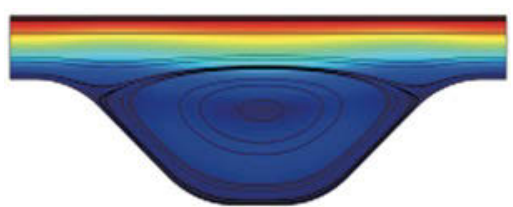

Kapur, N. et al.; A Review of Gravure Coating Systems.

Convertech \& e-Print 2011.

- If we assume Couette flow between web and gravure lands and gap equals $2 x$ liquid film thickness

- Avg $\dot{\gamma} \approx 300 s^{-1}$

Suggests time at high shear is most important 


\section{Conclusions}

- Slot die leads to better dispersed catalyst particles which leads to more homogenous distribution of catalyst and ionomer

- This results in more ionomer in contact with catalyst, leading to better performance

- Indicates time at high shear, not just shear rate is important for high performance catalyst layers 


\section{Acknowledgements}

\section{NREL}

- Min Wang

- Tim Van Cleve

- KC Neyerlin

- Mike Ulsh

U.S. Department of Energy, Hydrogen and Fuel Cell Technologies Office

- Nancy Garland

\section{Colorado School of Mines}

- Samantha Medina

- Svitlana Pylypenko 


\section{Thank You}

\section{www.nrel.gov}

NREL/PR-5900-77815

This work was authored, in part, by the National Renewable Energy Laboratory, operated by Alliance for Sustainable Energy, LLC, for the U.S. Department of Energy (DOE) under Contract No. DE-AC36-08G028308.

Funding provided by U.S. Department of Energy, Office of Energy Efficiency and Renewable Energy, Hydrogen and Fuel Cell Technologies Office. The views expressed in the article do not necessarily represent the views of the DOE or the U.S. Government. The U.S. Government retains and the publisher, by accepting the article for publication, acknowledges that the U.S. Government retains a nonexclusive, paid-up, irrevocable, worldwide license to publish or reproduce the published form of this work, or allow others to do so, for U.S. Government purposes.
GNREL

Transforming ENERGY 


\section{Materials and Methods}

- Catalyst: Pt on high surface area carbon (TKK TEC10E50E)

- Ionomer: Nafion, 1000 EW (Ion Power D2020)

- Membrane: Nafion, 1000 EW, 25 um (Nafion NR211)

- Diffusion Media: Freudenberg H23C8

- Catalyst ink - 3.2 wt\% PtHSC

- Ink Dispersion: High shear mixer (Ika Ultra Turrax)

- Gravure Coating

$-1 \mathrm{~m} / \mathrm{min}$

- Air floatation oven: $80{ }^{\circ} \mathrm{C}$ 